\section{NASA tunes in to nuclear power}

\section{Tony Reichhardt, Washington}

NASA plans to make major new investments in nuclear-powered rockets and spacecraft, its recently appointed head Sean O'Keefe said on 4 February as he unveiled the agency's budget proposal for the fiscal year 2003. But at $\$ 15.1$ billion, NASA's budget would be virtually unchanged from this year.

O'Keefe added that proposed missions to Jupiter's moon Europa and to Pluto will be scrapped to be replaced with a widerranging programme called New Frontiers, modelled after the agency's successful Discovery line of planetary spacecraft.

With a typical mission price tag of about $\$ 650$ million, New Frontiers will focus on studying the origins of life in the Solar System, as well as other priorities set by a forthcoming review of planetary exploration by the National Academy of Sciences. NASA will solicit mission concepts from laboratories inside and outside the agency this spring, and plans to choose the first winner next year.

The agency is set to make its first significant investments since the 1960s in space nuclear power ( $\$ 79$ million) and nuclear rocket propulsion ( $\$ 46.5$ million) during 2003. It sees these technologies as the best way to cut the time it takes to travel to the outer planets and to increase the working lives of probes and rovers sent to visit planets (see Nature 410, 626; 2001).

These and other technology investments account for much of the $12 \%$ increase in

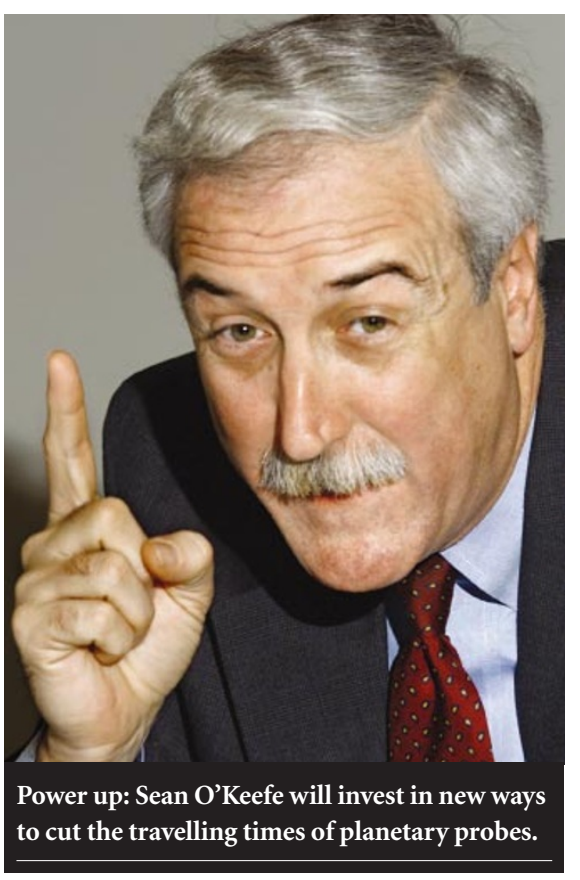

NASA's space-science budget, to \$3.4 billion. According the White House, the portion of NASA's total budget spent on research and development will grow by $5 \%$ to $\$ 10$ billion.

Funding for the troubled International Space Station drops by $13 \%$ to $\$ 1.5$ billion in the budget proposal. Agency managers have been given two years to solve its fiscal and managerial problems, or resign themselves to having a smaller, less capable station.

\title{
Extra duties offset NSF gains
}

\section{Virginia Gewin, Washington}

The National Science Foundation (NSF) has been put in charge of three new programmes in this week's budget proposal. But, despite being the only government agency praised for its financial management in a much-trumpeted recent White House assessment, it gets little financial reward.

The NSF — which funds most nonbiomedical university research in the United States - receives an increase of $5 \%$ in the budget proposed by its director, Rita Colwell. Government officials acknowledge that this is really worth just $3.4 \%$ when its new responsibilities are taken into account.

Under the proposal, the NSF will take charge of the Sea Grant programme, transferred from the National Oceanic and Atmospheric Administration; the environmental education programme at the Environmental Protection Agency; and a new water-quality programme to replace the toxic-substances hydrology programme at the US Geological Survey.

Apart from the new arrivals, the big winner at the NSF is the mathematics division (see Nature 414, 676; 2001), whose grant budget will grow by $\$ 30$ million to $\$ 180$ million. Other agency divisions, including astronomy, physics and chemistry, see their budgets fall by a few percentage points.

Two new major research projects that have been on hold for a year get the go-ahead in the budget. EarthScope, a network devoted to earthquake detection and research, will receive $\$ 35$ million and two prototype sites for the National Ecological Observatory Network will get \$12 million (see Nature 410, 854; 2001). Continued building of the Atacama Large Millimeter Array is allocated $\$ 30$ million.

And the impoverished graduate students supported by the foundation can look forward to an increase in their annual stipends, from $\$ 21,500$ to $\$ 25,000$.
Pentagon rise bypasses campuses

The budget will not do much for university researchers on the prowl for Pentagon funds despite its proposed \$5-billion hike in research and development at the defence department.

All of the increase is earmarked for weaponssystem development. The Department of Defense's $\$ 1.4$ billion in annual support for basic research will actually slip by $\$ 10$ million, while its appliedresearch funding slides by $7.5 \%$ to $\$ 3.8$ billion.

The main exception to this is the Defense Advanced Research Projects Agency, whose basic research programme will be boosted by almost a quarter to $\$ 176$ million, while its applied research budget grows by $15 \%$ to more than $\$ 1.2$ billion.

\section{Peer-review programme is rewarded}

The US Department of Agriculture said that it would double the funding next year for its National

Research Initiative (NRI), to \$240 million.

Unlike most research spending by the agriculture department, NRI grants are competitively peer-reviewed, making the programme popular with plant geneticists and other university researchers.

The rest of the agriculture department's research and development programmes would be cut back from $\$ 2.3$ billion this year to $\$ 2.1$ billion. But the department proposes small increases in funding for research into bovine spongiform encephalopathy and foot-and-mouth disease.

\section{Minority programmes win at WIH}

As expected, Anthony Fauci's National Institute of Allergy and Infectious Diseases (NIAID) is the biggest winner from Bush's proposal to increase the budget of the National Institutes of Health (NIH) by $16 \%$.

Under the proposal, the NIAID's budget would grow by $57 \%$ to $\$ 4$ billion, with most of the increase directed at bioterrorism research. The National Cancer Institute receives an increase of $12 \%$, and the National Center on Minority Health and Health Disparities will receive $18 \%$. Most other institutes would get an increase of 8-9\%.

Funds for HIV/AIDS research at the NIH grow by $10 \%$ to $\$ 2.8$ billion, including a $24 \%$ boost in vaccine research and $\$ 100$ million for an international fund to fight HIV/AIDS, malaria and tuberculosis.

\section{Technology scheme under siege}

One of the Clinton administration's favourite research programmes - the Advanced Technology Program (ATP) at the National Institute of Standards and Technology (NIST) - will be almost halved in size under the Bush proposal.

The proposal cuts the programme's budget from $\$ 185$ million to $\$ 108$ million. A similar plan to shrink the ATP — which the administration regards as an unnecessary subsidy for work that industry should do itself — was blocked by Congress last year.

This time, the administration also proposes extra construction funding for NIST, providing $\$ 67$ million for new laboratories at its main campuses in Gaithersburg, Maryland, and in Boulder, Colorado. 